\title{
DE PAI PARA FILHO: A COMPLEXIDADE E OS DESAFIOS DA GESTÃO DAS EMPRESAS FAMILIARES
}

\author{
FATHER TO SON: \\ THE COMPLEXITY AND THE CHALLENGES OF \\ MANAGEMENT OF THE FAMILY BUSINESS
}

\author{
Recebido 23/12/2010 \\ Aceito 16/01/2012 \\ Ernani Cesar de Freitas ${ }^{1}$ \\ Mauricio Barth ${ }^{2}$
}

\section{RESUMO}

As empresas familiares ocupam uma posição de destaque no âmbito dos negócios em virtude da sua contribuição para a economia brasileira. Muitas das grandes empresas do país são ou já foram familiares em sua essência; número que poderia ser ainda maior não fossem as complexidades enfrentadas por essas organizações durante suas gerações. Dessa forma, o presente trabalho aborda o tema gestão das empresas familiares, de modo a estudar as características de gestão, de governança, de profissionalização e de cultura organizacional, apontando, assim, contribuições para a imensa rede de empresas familiares brasileiras - o tipo mais frequente de organização no país. Nesse sentido, o objetivo geral deste estudo visou investigar e analisar essas principais características teóricas em empresas familiares de pequeno e médio porte, segmentadas no comércio do Vale do Sinos/RS. Para isso, o presente estudo foi fundamentado a partir de diversos autores, como Freitas e Frezza (2005), Bornholdt (2005), Casillas, Vázquez e Díaz (2007) e Adams (2009). Utilizou-se neste trabalho a pesquisa exploratória mediante estudo de casos múltiplos, por meio da coleta de dados feita a partir de entrevista não-estruturada. Constatou-se que algumas mudanças não ocorrem somente em função do aspecto profissionalização, mas sim pela forma de gestão e pelo processo decisório da empresa. Alguns desses processos, muitas vezes, são mais executados e mais trabalhados em algumas empresas familiares, no entanto, destaca-se que todos esses aspectos organizacionais deveriam fazer parte da dinâmica das organizações familiares.

Palavras-chave: Empresa Familiar. Profissionalização. Gestão. Governança. Cultura Organizacional.

\footnotetext{
${ }^{1}$ Pós-doutorado em Linguística Aplicada pela Pontifícia Universidade Católica de São Paulo (PUC-SP), Doutor em Letras Pontifícia Universidade Católica do Rio Grande do Sul (PUCRS); Professor na Universidade Feevale, Novo Hamburgo, Rio Grande do Sul, Brasil.E-mail: ernanic@feevale.br.

2 Pós-graduado em Gestão Estratégica de Marketing - Ênfase em Administração de Vendas pela Universidade Feevale; Bacharel em Comunicação Social - Habilitação em Publicidade e Propaganda pela Universidade Feevale, Novo Hamburgo, Rio Grande do Sul, Brasil. E-mail: mauricio@feevale.br.
} 


\section{ABSTRACT}

For his contribution to the Brazilian economy, family businesses occupy a prominent position within the business. Many large companies in the country are, or have already been familiar in its essence, that number could be even higher if not for the complexities faced by these organizations during their generations. Thus, this paper addresses the issue of family business management in order to study the characteristics of management and governance, professional and organizational culture, pointing thus contributions to the huge network of family businesses in Brazil - the most common type of organization in the country. Thus, the objective of this study was to investigate and analyze these theoretical main characteristics in family businesses small and medium-sized segmented in trade of the Vale do Sinos/RS. For this, the present study was based from various authors, such as Davis and Frezza (2005), Bornholdt (2005), Casillas, Vazquez and Diaz (2007) and Adams (2009). We used this exploratory work through multiple case study, by means of data collection done through unstructured interview. It was found that some changes occur not only in terms of professional appearance, but by way of management and business decision-making. Some of these processes are often performed more and more worked on some family business focus of this study, however, pointed out that all these aspects should be part of the organizational dynamics of family organizations object of this study.

Keywords: Family Business. Professionalization. Management. Governance. Organizational Culture.

\section{INTRODUÇÃO}

As empresas familiares são, com frequência, objeto de estudos e tema de discussões em virtude da sua grande representatividade na economia brasileira, pois exercem enorme influência, seja em termos de produtividade ou de empregabilidade, possuindo, ainda, um grande potencial de desenvolvimento. Sendo assim, este estudo abordou o tema gestão das empresas familiares, dada a sua relevância e a importância em conhecer como essas empresas lidam com sua a administração, operacionalização e continuidade do empreendimento. Justifica-se, então, este estudo pela contribuição, em termos de subsídios, que poderá oferecer às empresas familiares de pequeno e médio porte, do segmento serviços, no que tange às boas práticas de gestão, de governança, de profissionalização, todas essas variáveis organizacionais, que formam um conjunto inter-relacionado e harmônico, as quais impactam os rumos e a perpetuidade dessas organizações.

Este estudo foi fundamentado buscando analisar possíveis respostas para a sua problematização. Nesse sentido, identificam-se as seguintes questões norteadoras que problematizam a pesquisa: como a gestão e a governança das empresas familiares estudadas se apresentam em relação à profissionalização da empresa? Qual(is) processos de profissionalização são encontrados nessas empresas familiares? A cultura organizacional influi na governança dessas empresas?

Esta pesquisa teve como objetivo geral investigar e analisar os processos de gestão, de governança, de profissionalização e de cultura organizacional em empresas familiares de pequeno e médio porte, do segmento de comércio, na região do Vale do Sinos/RS, com a finalidade de entender e relacionar a repercussão desses processos na realidade organizacional das empresas pesquisadas. Como desdobramento e ações decorrentes do objetivo geral, foram estabelecidos os seguintes objetivos específicos: a) observar e compreender o processo de gestão e de governança nas empresas estudadas; b) entender e avaliar como ocorre a profissionalização nas empresas familiares pesquisadas; c) identificar e analisar aspectos da cultura organizacional das empresas familiares estudadas e os seus impactos nos processos de profissionalização da gestão e da governança.

Em relação aos procedimentos utilizados, o estudo alinhou-se a uma pesquisa exploratória, adotando o delineamento de estudo de casos múltiplos. Nesse contexto, o estudo caracteriza-se, quanto à abordagem das questões norteadoras do problema, como qualitativo com 
amostragem não-probabilística, classificada como intencional. Sobre a técnica de coleta de dados, o estudo adotou entrevistas não-padronizadas, utilizando-se do resultado dessas entrevistas para análise e interpretação dos dados coletados.

A seguir, apresentam-se as seções sobre a fundamentação teórica, os procedimentos metodológicos, o estudo de caso, a caracterização das empresas estudadas, os resultados e a análise e, por fim, as considerações finais.

\section{EMPRESA FAMILIAR}

A abordagem da gestão da empresa familiar vem, constantemente, gerando maior discussão em salas de aula, escritórios administrativos e de consultoria, bem como em palestras acadêmicas. Segundo Freitas e Frezza (2005), no Brasil, mais de 99\% dos negócios empresariais são familiares. Também, conforme esses autores, nestas empresas empregam-se mais de $60 \%$ da mão-de-obra que atua no mercado de trabalho. Sendo assim, observa-se que empresas familiares possuem grande influência na economia e no desenvolvimento do país, seja no âmbito local, regional ou nacional.

Atualmente, há muitos conceitos para empresa familiar. Casillas, Vázquez e Díaz (2007) comentam sobre a dificuldade de obter uma definição clara e consensual sobre este tema, pelo fato de os negócios familiares serem realidades multidimensionais, motivo pelo qual há definições baseadas em múltiplos fatores. Porém, esses autores afirmam que a maioria dos conceitos gira em torno de três aspectos principais, que são:

- a propriedade ou controle sobre a empresa;

- o poder que a família exerce sobre a empresa, normalmente pelo trabalho nela desempenhado por alguns membros desta família;

- a intenção de transferir a empresa a futuras gerações e a concretização disso na inclusão de membros da nova geração na própria empresa.

Dessa forma, mesmo existindo diversos conceitos para empresa familiar, são considerados os aspectos citados em praticamente todas as definições. Adams (2009) define empresa familiar como aquela em que a propriedade e as decisões são controladas pelos membros de um grupo de afinidade afetiva. Essa definição de Adams (2009) é a que norteia este estudo. A esse respeito, Bornholdt (2005) acrescenta que em uma empresa familiar as crenças e os valores da organização identificam-se com os da família, sendo que o controle acionário pertence a esta e/ou a seus herdeiros.

Desse fato é que, normalmente, a empresa familiar surge da iniciativa de um empreendedor, seguindo um projeto, um sonho ou desafio de vida. Muitas dessas empresas foram edificadas por seus fundadores com o objetivo de criar um negócio pensando no futuro de seus filhos. Para Grzybovski e Tedesco (2000, p. 64), "[...] o nível de participação de membros da família na gestão da empresa é fortemente influenciado pelas motivações que levaram o empreendedor a criar seu próprio negócio". A preocupação do empreendedor quando funda uma empresa é gerar lucros e prosperar, para que a empresa possa seguir seu caminho de sucesso enquanto está sob seu comando e quando for repassada ao seu sucessor.

A maioria das empresas familiares tem como principal gestor e administrador o próprio dono da empresa, o que, muitas vezes, pode ocasionar problemas na administração. Sobre isso, Robbins (2005) observa que, em muitas empresas familiares, o gestor precisa diferenciar os interesses da família e os da empresa, buscando minimizar os conflitos entre família e negócio. Essa diferenciação dos interesses proporcionaria ao gestor um equilíbrio na administração da empresa e dos interesses da família. 
Nesse sentido, a complexidade que se reveste a gestão e governança da empresa familiar requer processos de descentralização do poder, para que, no futuro, a administração da empresa não tenha problemas com familiares e colaboradores. Conforme Bernhoeft e Gallo (2003), um processo de descentralização é estabelecido no intuito de delegar as atividades da gestão e do cotidiano da empresa a um corpo gerencial contratado, sendo ele conhecido ou não da família. Porém, o processo de descentralização do poder nas empresas ocasiona mudanças nas formas de administrar, de profissionalizar e de planejar as suas estratégias, fatores esses que também impactam a cultura organizacional dessas organizações familiares.

Na maioria das vezes, as mudanças realizadas pelos proprietários das empresas surgem devido a alguma dificuldade encontrada no trabalho ou a uma crise financeira. Entretanto, para Morais (2009), essas mudanças podem ser de difícil implantação em grande parte das empresas de pequeno e médio porte, por isso, faz-se necessário buscar mudanças de fácil implementação e que sejam gradualmente aplicadas, o que poderia proporcionar à empresa melhores resultados.

A seguir, serão abordados os temas gestão e governança visto sua relevância no contexto e no cotidiano das empresas familiares.

\subsection{Gestão e governança}

A governança na empresa familiar surgiu através do conceito de governança corporativa. Para Bornholdt (2005, p. 26), "[...] o sentido mais conhecido da governança corporativa se refere à relação entre a empresa, os acionistas, os mecanismos e os princípios que governam o processo decisório da gestão, principalmente em relação à proteção dos acionistas". Este tipo de governança busca demonstrar a importância da utilização de sistemas e métodos na tomada de decisões de uma empresa, para que proprietários e sócios tenham certeza de que as decisões estão sendo tomadas conforme sistemas estabelecidos.

No entanto, a governança nas empresas familiares deve ser mais cautelosa, pois o trabaIho realizado com membros da família pode gerar conflitos entre gestores, familiares e herdeiros. Para Casillas, Vázquez e Díaz (2007), as empresas familiares, embora tenham suas peculiaridades, devem elaborar um programa de governança adequado para suas características, garantindo a defesa de todos que estão nela envolvidos.

Para que a implementação de um sistema de gestão empresarial ocorra sem maiores riscos, Bornholdt (2005) afirma que esse processo deve iniciar baseado no planejamento estratégico. O planejamento estratégico de uma empresa familiar vem se tornando cada vez mais importante, pois visa o futuro da empresa e da família que a administra. Para Oliveira (1999, p. 49), "[...] o planejamento estratégico deve considerar toda a empresa e não apenas uma de suas partes". 0 planejamento serve como um rumo a ser tomado pela empresa. Com base no que foi planejado, fica mais fácil à família gestora executar os processos, controlar seus custos e o desenvolvimento dos projetos, para colocar em prática tudo que foi avaliado no planejamento (CAVE, 2009).

Assim, para ocorrer de forma satisfatória, no planejamento devem ser considerados alguns aspectos como o cenário onde a empresa se encontra, as ameaças e oportunidades que surgem, os pontos fortes e fracos da empresa. Bornholdt (2005) destaca três principais itens críticos estratégicos, que são: tecnologia (capacidade de atualização tecnológica e seu desenvolvimento a longo prazo); capital (a demanda de capital para o crescimento ou para investimentos); e gestão (a gestão e a necessidade de pessoas para uma administração competente).

A gestão eficiente implica necessariamente uma governança eficaz; nesse sentido, é imperioso destacar a importância de que se reveste a função controle na empresa familiar. Para 
isso, cria-se o conselho familiar que, na concepção de Casillas, Vázquez e Díaz (2007), é composto por membros da família que se reúnem para discutir políticas e mecanismos capazes de enfrentar possíveis problemas que possam ocorrer devido a conflitos entre objetivos empresariais e familiares. O conselho de família, de acordo com Bornholdt (2005, p. 95), “[...] é um órgão deliberativo que administra o cotidiano das famílias empresárias e seu inter-relacionamento com os sistemas societários e empresariais", e que, segundo o mesmo autor, "[...] a escolha dos conselheiros familiares geralmente obedece a critérios associados à participação de capital nas empresas" (BORNHOLDT, 2005, p. 95).

Em relação ao controle do planejamento estratégico, as empresas familiares de grande porte criam conselhos administrativos, visto que, segundo Casillas, Vázquez e Díaz (2007), o conselho de administração é o mecanismo de controle para que o comportamento da alta direção esteja de acordo com os interesses dos familiares. "A missão do conselho de administração pretende 'converter' os conselheiros numa ideologia da organização para as atitudes e as condutas dos conselheiros de acordo com as das famílias sócias" (BORNHOLDT, 2005, p. 114). Não obstante esse autor referir-se às empresas familiares de grande porte, entendemos, no âmbito deste estudo, que, analogamente, as organizações familiares de pequeno e médio porte também podem valer-se da figura do conselho administrativo, porém, de forma mais flexibilizada, ou seja, no formato de um conselho ou comitê gestor.

Com a governança e o controle feitos de forma correta e eficaz, a empresa familiar alinha-se ao caminho adequado da gestão organizacional, para a otimização da administração, tanto empresarial quanto familiar (FREITAS, 2009). Além desses aspectos, outro importante fator que deve ser levado em consideração no planejamento das empresas familiares é a profissionalização, que será abordada a seguir, visto a estreita relação dessa com a gestão e a governança em organizações do tipo familiar.

\subsection{Profissionalização e gestão}

Toda empresa familiar precisa, em sua gestão e governança, passar por processos de profissionalização, pois entende-se que uma empresa sem gestores profissionais na área administrativa está fadada ao insucesso. A profissionalização na gestão familiar é um fator extremamente relevante, pois, segundo Padula (1998), significa o ato ou o efeito de realizar atividades remuneradas como meio de vida utilizando métodos e princípios. Para Freitas e Frezza (2005, p. 35), "[...] a profissionalização é o processo pelo qual uma organização familiar ou tradicional assume práticas personalizadas". Este é um processo no qual há integração de gerentes contratados e assalariados, junto aos administradores familiares, e no qual é adotado um código de conduta para esse grupo de trabalhadores.

A profissionalização dentro da empresa familiar requer cuidados redobrados, pois, neste tipo de organização, existem fortes laços de relacionamento entre sócios, familiares e herdeiros. Esses traços culturais, quando mal-orientados, podem acarretar problemas na hierarquia, na sucessão e, até mesmo, gerar uma provável desconfiança entre os familiares. Conforme Gehlen (2006, p. 25), "[...] a profissionalização começa a ocorrer quando a organização deixa de ser apenas um negócio de família para tornar-se uma empresa profissional". Contudo, para Freitas e Frezza (2005), a gestão profissionalizada não pode ser considerada imune às influências familiares. Se a propriedade da empresa muda em função do fator "herança", então os herdeiros poderão influenciar na condução do empreendimento. Logo, herdeiros mal preparados para a sucessão poderão provocar grandes estragos na empresa, por consequência, com repercussões negativas 
e até mesmo comprometedoras quanto à continuidade do empreendimento.

Assim, para a eficácia da gestão e da sua respectiva profissionalização, outro aspecto que deve ser bem planejado, evitando, assim, problemas futuros quanto à gestão, diz respeito à sucessão na empresa familiar. $O$ sucessor deve ser um profissional capaz de gerir a empresa e dar continuidade àquilo que está indo bem e solucionar, da melhor maneira possível, eventuais problemas que ocorram na sua gestão. Casillas, Vásquez e Díaz (2007) advertem que o sucesso de uma boa profissionalização da gestão em uma empresa familiar passa pela certeza de que os dirigentes possuem habilidades e competências suficientes para desenvolverem suas funções empresariais, e assim obterem êxito nas atividades de gestão e de governança do negócio. No entanto, em alguns casos, não se encontram nos familiares pessoas profissionalizadas competentes para gerir a empresa, por isso a busca por profissionais fora da família se torna inevitável para que o empreendimento não tome rumos decrescentes em sua expansão, o que pode ocasionar perda de competitividade no mercado em que atua e, até mesmo, problemas quanto à sua perpetuidade.

Diante de cenários, de elevada competitividade, desafiadores para a gestão, que requer sua profissionalização, a empresa familiar busca em sua cultura organizacional as apropriações para sua profissionalização. Isto se dá através de seus princípios e valores, da sua estrutura, da sua forma de gestão e de seus executivos, pois é através das características de sua cultura que a empresa conseguirá programar um trabalho mais específico para a profissionalização da sua gestão. É sobre isso que se comenta na próxima seção.

\subsection{Cultura organizacional - importância para a gestão e profissionalização}

As empresas, quando fundadas, já possuem uma cultura histórica vinda da família, seus costumes, suas crenças, seus princípios e valores. Segundo Bornholdt (2005, p. 20), "[...] a cultura organizacional é formada pela história por meio de mitos e atos heróicos; pela ideologia das crenças e valores, pela filosofia da prática das éticas, pelo negócio e suas peculiaridades e pelos rituais e atos pautados e repetitivos". Nesse sentido, por um lado, Oliveira (1999, p. 40) comenta que "[...] a cultura organizacional é representada pelo conjunto de crenças, valores e percepções que consolida uma forma de ser da empresa, uma espécie de personalidade empresarial”. De outro lado, Coker (2009) incluiu, além dos princípios e valores como importantes conjuntos para formação da cultura, os artefatos, que são formados por objetos considerados tradicionais na empresa ou por expressões audíveis.

Toda empresa familiar não pode deixar de lado essa cultura de organização, pois é ela que forma a identidade da empresa, mostrando para os consumidores e clientes como é o trabalho dentro da empresa, sua cultura histórica e seus métodos. Davel e Colbari (2000) comentam que a cultura organizacional forma os vínculos e os laços que geram a união dos colaboradores em torno da identidade da empresa, além dos familiares que estão vinculados a uma organização empresarial. Os vínculos familiares na organização efetivam cada vez mais o poder da cultura organizacional na empresa.

A formação da cultura, conforme Mincer (2009), é dada pelo compartilhamento de experiências e pela realização de um aprendizado em comum, principalmente por quem lidera a organização. Essas pessoas vão complementando e compartilhando seus valores, passando de uma soma de sujeitos para um grupo de indivíduos que possuem os mesmos sentimentos e valores. Conforme o grupo adquire mais experiência na resolução de problemas, este estabelecerá princípios válidos para todos os membros da organização.

Desse modo, ass empresas conseguem, diante de princípios organizacionais equalizados, manter sua cultura por muito tempo devido a esses processos de evolução que o grupo de 
colaboradores implanta dentro de suas vidas, tanto no âmbito pessoal quanto profissional. Os colaboradores, juntamente com os familiares da empresa, são os principais disseminadores da cultura organizacional para seus consumidores. Conforme Bornholdt (2005, p. 20), "[...] a evolução da cultura organizacional em torno da empresa familiar difere dos indivíduos, ou seja, da individualidade daqueles que a compõem".

Quanto à evolução da cultura organizacional em uma empresa familiar, entende-se ser necessário contar com a influência de um grande líder. Segundo destaca Segrè (2009), esse líder deve manter o poder por um longo período, pois, assim, forma a cultura de acordo com suas preferências e estilos. Entretanto, nem todos os novos colaboradores já entram na empresa sabendo como funciona sua cultura organizacional. Para isso, torna-se importante que se ative um processo de educação deste novo colaborador, mostrando a ele os princípios e valores que a empresa professa. Segundo Casillas, Vásquez e Díaz (2007, p. 36), “[...] é preciso uma intensa e, ás vezes, prolongada convivência entre os membros da geração precedente e as pessoas que se incorporaram". A forma de incluir um novo colaborador na organização pode ser feita através de sua vivência com o grupo de colaboradores que estão na empresa há mais tempo ou, até mesmo, na vivência com os familiares que trabalham na organização, proporcionando, assim, um maior entendimento dos princípios e valores difundidos pela corporação no seu dia-a-dia.

Na próxima seção, apresentam-se os procedimentos metodológicos utilizados neste estudo.

\section{METODOLOGIA}

Para que a compreensão sobre o estudo se desenvolva de maneira eficaz, esta seção apresenta os métodos e técnicas de pesquisa utilizados para a obtenção dos objetivos propostos. Quanto aos fins, a proposta metodológica definida para o estudo é identificada por uma pesquisa exploratória. Segundo Prodanov e Freitas (2009, p. 62), este tipo de pesquisa "[...] tem como finalidade proporcionar mais informações sobre o assunto que vamos investigar, possibilitando sua definição e seu delineamento". Gil (2006) a considera uma pesquisa com a finalidade de desenvolver, esclarecer e modificar conceitos e ideias, proporcionando a formulação de problemas mais precisos e criando hipóteses para futuras pesquisas.

Quanto aos meios, foi utilizada a pesquisa bibliográfica que, conforme Prodanov e Freitas (2009) é desenvolvida por meio de materiais já publicados, como livros, revistas, artigos científicos, monografias, entre outros. Este tipo de pesquisa permite conhecer diferentes visões e processos de gestão e de governança das empresas familiares, contribuindo para o desenrolar da análise e da interpretação dos dados.

Além da pesquisa bibliográfica, no presente trabalho empregou-se o procedimento de estudo de casos múltiplos. Segundo Yin (2005), o estudo de casos múltiplos como estratégia de pesquisa é utilizado para aumentar o conhecimento já existente sobre fenômenos individuais, sociais, políticos e organizacionais. Assim, realizou-se um estudo de caso de empresas localizadas no Vale do Sinos/RS, administradas por familiares. Nessas organizações, foram estudados três fenômenos: a forma de gestão e de governança, sua profissionalização e sua cultura organizacional, buscando, assim, acrescentar informações que, no momento, eram desconhecidas aos pesquisadores. De acordo com Prodanov e Freitas (2009, p. 74), “[...] por lidar com fatos/fenômenos normalmente isolados, o estudo de caso exige do pesquisador grande equilíbrio intelectual e capacidade de observação ('olho clínico'), além de parcimônia (moderação) quanto à generalização dos resultados". Dessa forma, para a realização deste estudo de casos múltiplos, as informações foram coletadas por meio de entrevistas não-padronizadas com os diretores e gerentes das empresas estudadas. 
A abordagem das questões que problematizaram o estudo ocorreu de forma qualitativa. Conforme Gil (2006), a abordagem do problema define as pesquisas de estudo de caso como procedimentos analíticos de natureza qualitativa, pois não há fórmulas ou receitas predefinidas para orientar o pesquisador, fazendo com que a análise dos dados na pesquisa qualitativa dependa muito da capacidade e do estilo do pesquisador. "A utilização deste tipo de abordagem difere da abordagem quantitativa pelo fato de não utilizar dados estatísticos como o centro do processo de análise de um problema [...]" (PRODANOV; FREITAS, 2009, p. 81).

Sobre o universo ou população-alvo da pesquisa, foram utilizadas empresas de pequeno e médio porte, do segmento serviços, localizadas na região do Vale do Sinos. Essas empresas, em número de seis, constam de banco de dados dos pesquisadores, e foram escolhidas pelo critério de acessibilidade visto terem se manifestado favoravelmente a participar da pesquisa quando consultadas. Nas empresas selecionadas para este estudo, foram preferenciados respondentes que atuam em cargos de direção e de gerência nas organizações foco, ao todo 12 entrevistas realizadas. Dessa forma, foi utilizada amostra não-probabilística intencional que, segundo Gil (2006, p. 94), "[...] consiste em selecionar um subgrupo da população que, com base nas informações disponíveis, possa ser considerado representativo de toda a população".

A técnica de coleta de dados utilizada para o estudo foi entrevista não-padronizada que, segundo Prodanov e Freitas (2009), é utilizada quando se quer explorar mais questões sem a rigidez de um roteiro. Para isso, utilizaram-se perguntas realizadas individualmente e transcritas, simultaneamente, para um computador portátil. Sendo assim, responderam à entrevista familiares que possuem cargos de direção dentro das empresas estudadas. Foram selecionados para as entrevistas os dois principais gestores de cada organização em estudo, os quais responderam a pesquisa, em novembro de 2009.

Destarte, o pesquisador realizou a análises das entrevistas, buscando evidenciar pontos em comum nos depoimentos dos entrevistados, bem como confrontá-las. Conforme Gil (2006, p. 156), "[...] a análise tem como objetivo organizar e sumariar os dados de forma tal que possibilitem o fornecimento de respostas ao problema proposto para investigação". Na análise e interpretação dos dados, analisou-se o conteúdo obtido nas entrevistas, com base na fundamentação teórica realizada de forma qualitativa. Não se adotou um modelo específico para análise dos dados coletados, pois entendeu-se que o conjunto das variáveis, categorias específicas - gestão e governança, profissionalização e cultura organizacional - de maneira inter-relacionada e coesa forma um todo harmônico que possibilitou efetivar a análise a partir do instrumental de pesquisa - a entrevista. Sobre isto, Marconi e Lakatos (1999, p. 36) ressaltam: "[...] uma vez manipulados os dados e obtidos os resultados, o passo seguinte é a análise e interpretação destes, constituindo-se ambas no núcleo da pesquisa".

A seguir, apresenta-se cada caso estudado, nos quais são evidenciados os resultados obtidos na pesquisa e na respectiva análise.

\section{ESTUDO DE CASOS MÚLTIPLOS}

Pela sua importância na economia mundial, há muitos anos as empresas familiares são objeto de estudo de diversos pesquisadores. Segundo Freitas e Frezza (2005), a empresa familiar é provavelmente uma das mais antigas formas de negociação praticadas na evolução da humanidade. E a preocupação com suas formas de gestão, com sua profissionalização e com sua cultura tem sido cada vez maior, devido a problemas encontrados na maioria dessas empresas. 


\subsection{Caracterização das empresas}

A seguir, será apresentada uma breve caracterização dos aspectos que se destacam em cada uma das empresas de pequeno e médio porte estudadas, segmento comércio. Os nomes das empresas foram atribuídos ficticiamente.

a) Irmãos B. Ltda (Sapiranga/RS): esta empresa nasceu em meados de 1975 sendo que, em 1977, o proprietário repassou a empresa aos seus três filhos. Com o crescimento e sucesso da empresa, duas filiais surgiram na cidade de Riozinho/RS. Atualmente, a empresa está na segunda geração, trabalhando com nove funcionários na matriz e um funcionário na filial, sendo, assim, considerada uma empresa de pequeno porte.

b) TC Componentes para Calçados Ltda (Novo Hamburgo/RS): esta empresa atua no ramo calçadista e na indústria da borracha, direcionando suas atividades ao comércio doméstico. A Empresa foi fundada em 1993 por dois primos, primeira geração da empresa, os quais já possuíam experiência no mercado de calçados quando oportunizaram seus conhecimentos para iniciarem uma empresa em sociedade. De porte pequeno, a Empresa possui vinte e um funcionários divididos por funções e setores.

c) Farmácias CB e Rede (Campo Bom/RS): empresa fundada em 1ㅇ de outubro de 1965 por Remi Steigleder, farmacêutico, que hoje divide a administração da empresa com seu filho e sua nora, gestão em fase de sucessão. Atualmente, é uma empresa considerada de pequeno porte, contando com trinta funcionários, os quais desempenham diversas atividades na empresa. A organização atua no ramo farmacêutico e tem como principal objetivo comercializar remédios e perfumaria.

d) Beta Beneficiamento de Couros Ltda (Novo Hamburgo/RS): a empresa, também denominada de curtume, tem sua área de atuação voltada para o ramo coureiro-calçadista, vendendo e beneficiando artigos em couro, contando com o número de oitenta e quatro funcionários, sendo uma empresa de pequeno porte, encontra-se em sua gestão na fase de migração para segunda geração. Durante a sua existência, a empresa passou por diversas modificações para se manter no mercado, devido às crises que ocorreram nesse período no ramo coureiro-calçadista. Na sua primeira década de existência, a organização tinha sua produção totalmente voltada para o mercado externo, produzindo napas macias pigmentadas e demais artigos tidos como tradicionais. Porém, com a diminuição nas exportações, devido a fatores externos, como cotação da moeda e demanda, a empresa voltou-se para o mercado interno, tendo se reestruturado para atender as suas exigências.

e) U\&N Transporte (São Leopoldo/RS): empresa de médio porte fundada em 8 de abril de 1969, atuando no ramo de serviços. Apresenta-se na sua gestão em fase de transição para a segunda geração. A empresa possui filiais que foram, estrategicamente, espalhadas pelo Brasil, as quais localizam-se em Araucária/PR, Betim/MG, Paulinea/SP e Guarulhos/SP. Ainda, possui duas filiais que são como braços logísticos da empresa em Triunfo/RS e Taboão da Serra/SP. Hoje, a empresa conta com sessenta e oito veículos próprios e personalizados de acordo com a necessidade do cliente, e uma base de trezentos colaboradores diretos, tendo clientes como Braskem, Ipiranga, Gerdau, Emplal, Usiminas, entre outros.

f) Estofados Estilo (Picada Café/RS): esta empresa foi fundada por três irmãos em dezembro de 1985 e atua como uma estofaria. Atualmente, a empresa está caracterizada como porte médio, ainda sob a gestão do fundador, conta com aproximadamente cento e cinquenta colaboradores diretos e indiretos, trezentos clientes ativos e sessenta fornecedores, atendendo, aproximadamente, à produção de 80 modelos diferentes de estofados. 


\subsection{Resultados e análise}

Este tópico apresenta os resultados e a análise das entrevistas feitas com os representantes das seis empresas selecionadas para o estudo. A entrevista foi composta com perguntas referentes à gestão e à governança, à profissionalização e à cultura organizacional; foram entrevistados familiares que atuam no segmento da alta gerência das empresas analisadas. Procuramos seguir, em todas as empresas analisadas, o mesmo roteiro de respostas obtidas para as questões formuladas, no entanto, destacamos que apresentamos o que de mais essencial foi registrado nos depoimentos dos entrevistados, por isso em algumas empresas comentadas não há menção a algumas questões/respostas que constam em outras dessas organizações estudadas.

\subsubsection{Gestão e governança}

Na empresa Irmãos B. Ltda, constatou-se, através das entrevistas feitas, que a gestão ocorre de maneira informal, com base na experiência acumulada, não há planejamento estratégico estruturado. $\mathrm{O}$ que ocorre em termos de planejamento é o operacional, cuja demanda acontece no dia-a- dia. Percebeu-se que os processos decisórios concentram-se na figura dos dois principais proprietários, existindo assim pouca flexibilização quanto à tomada de decisões.

Assim, quando questionou-se sobre a existência de um planejamento estratégico formal e organizado, obteve-se como resposta de ambos entrevistados a inexistência de um planejamento formal devido à falta de tempo e vontade; conforme um dos entrevistados, "[...] se pensa e se executa no momento que é pensado. Sempre que se planeja há uns escorregões no que é planejado. Uns $30 \%$ do que se planeja é realizado, o resto é executado por impulso ou por necessidade primária". Perguntou-se ainda sobre as qualidades consideradas pelos líderes no momento da contratação de um novo funcionário, sendo ele familiar ou não. Os entrevistados, em poucas palavras, declararam ser mais conveniente contratar alguém com boas qualidades, pessoas conhecidas ou indicadas por alguém, com bom relacionamento e com conhecimento na função que irá atuar, embora em muitos dos casos se dê oportunidade para jovens sem experiência e sem vícios de outros empregos.

Em termos de gestão de pessoas, existem lacunas a serem preenchidas, tais como realização de treinamentos externos para aperfeiçoamento dos gestores e dos funcionários, poucos incentivos à formação profissional - acadêmica ou profissional. Destaca-se ainda o fato de a empresa não trabalhar com um planejamento de promoção e ascensão profissional, reduzindo desta maneira a possibilidade de crescimento da autoestima dos funcionários pelas promoções de cargos e salários, o que pode acarretar, assim, o baixo rendimento profissional, fazendo com que seus funcionários se sintam desvalorizados. Para Gehlen (2006), os valores desses funcionários que formam as organizações conduzem por sua vez à formação da cultura, sendo que em uma organização a ascensão profissional é um valor pessoal de cada funcionário.

A grande vantagem da empresa Irmãos B. Ltda com relação à cultura organizacional é a aproximação da empresa com a cultura de quem se localiza ao redor dela, seus clientes, funcionários e consumidores em geral. O fortalecimento da cultura ocorreu pelo fato de a empresa crescer junto com a comunidade que está à sua volta. $\mathrm{O}$ crescimento do bairro onde se localiza verificou-se pelo crescimento da empresa, através do fornecimento dos materiais por aqueles que ali vinham habitar. Assim, pode-se dizer que a cultura da empresa tem a cultura do bairro. Porém, a cultura das empresas familiares proporciona dificuldades em alguns aspectos da gestão. Assim, perguntou-se aos entrevistados qual a maior dificuldade encontrada na cultura organiza- 
cional da empresa, para sua gestão. Constatou-se, segundo um dos entrevistados: "[...] dificuldade de comunicação entre a família e os colaboradores, sendo que a cobrança dos erros é pouco praticada; isso se deve por ser uma empresa familiar, cuja gestão ainda está centrada na prática tradicional, ou seja, sempre se fez assim, para que mudar se está dando certo [...]".

A empresa TC Componentes para Calçados Ltda foi uma das empresas familiares pesquisada. Nela, percebeu-se existir uma cultura de centralização do poder e de decisões com os proprietários, de modo que isso dificulta o foco dos administradores em desenvolver a empresa, pois ficam ocupados em resolver pontualmente cada situação. No entanto, os gestores entendem que a profissionalização e a mudança da cultura organizacional são necessárias para o desenvolvimento sustentável dessa empresa.

Em relação a planejamento estratégico, foi destacado pelos entrevistados que há exercícios esporádicos nos sentido de formalizar o que é discutido, em função dos fatos que ocorrem cotidianamente, porém esse avanço ainda não se tornou possível. Isso se deve ao fato de outras atividades concorrentes, do dia a dia, se sobreporem ao processo que deveria ser organizado em reuniões de cunho gerencial e estratégico, e não operacional como hoje se verifica. A esse respeito, Oliveira (1999, p. 41) afirma: "[...] todo e qualquer tipo de planejamento procura estabelecer uma situação futura desejada e os meios para se alcançar essa situação, ou aproximar-se de tal situação. Nesse contexto, o planejamento aparece como ponto inicial no processo administrativo nas empresas [...]".

No que diz respeito à profissionalização, observou-se que o treinamento interno ocorre somente diante de necessidades surgidas pela execução processual; treinamentos externos são de natureza restrita e esporádica, em virtude da demanda de serviços cotidianos e também por esse quesito não fazer parte da cultura da empresa - que só volta mais ao emergente, inadiável, e não a questões de médio e longo prazos.

Seguindo na abordagem de profissionalização, abordou-se na TC Componentes para Calçados Ltda como ocorrem as decisões. A forma de estrutura na empresa é centralizada, não existem conselhos administrativos, pois a organização encontra-se na primeira geração. Dessa forma, as decisões na empresa são tomadas pelos dois gestores e proprietários que, quando não possuem conhecimento do caso, procuram, através de reuniões, discutir o assunto com os envolvidos e colaboradores que podem contribuir. De acordo com Segrè (2009), para uma empresa familiar perpetuar, torna-se necessária a clareza quanto à forma como são tomadas as decisões, contemplando e separando relações familiares, patrimônio e empresa.

A respeito da profissionalização na empresa estudada, os entrevistados afirmaram que a empresa não é profissionalizada, pois seus proprietários fazem parte das funções operacionais, além de estarem satisfeitos com a administração até o momento. Os entrevistados salientaram que apenas existem indícios de que o empreendimento esteja iniciando esse processo de profissionalização. Para Casillas, Vázquez e Díaz (2007, p. 30), “[...] a empresa familiar tem graves dificuldades para encarar a necessidade de renovação organizacional. [...] isto está ligado ao predomínio dos critérios familiares sobre os empresariais e ao estilo de administração dos seus líderes [...]".

$\mathrm{Na}$ empresa TC Componentes para Calçados Ltda, quanto à cultura organizacional, foi indagado se a cultura da empresa está aderente às condições atuais do mercado. Apesar dos pontos positivos destacados, os entrevistados, em consenso, posicionaram-se que a cultura poderia ser modificada para estar mais adequada aos requisitos exigidos pelo mercado, em relação a se tornar uma empresa que busca crescimento e desenvolvimento, pois a concorrência, em meio à crise, não quer mais somente sobreviver. Para Cave (2009), com o tempo, as culturas podem tornar-se muito estáveis, mas nunca estáticas. Seguindo esse entendimento, Mincer (2009) comenta que o estado inercial causa sérios danos para a organização, com interferência direta 
nos seus resultados.

Nas Farmácias CB e Rede, segundo relatos dos entrevistados, a empresa possui uma gestão profissionalizada. Um dos entrevistados disse que "[...] a profissionalização na empresa familiar consiste em planejar, dirigir e controlar. A empresa possui uma gestão profissionalizada, sendo realizado um planejamento onde são estabelecidas metas a serem alcançadas, as quais são controladas e, se preciso, modificadas, havendo uma avaliação de desempenho tanto dos objetivos a serem alcançados, quanto dos colaboradores que atuam na empresa". Outro entrevistado ressaltou que "[...] é a base fundamental para o sucesso da empresa, onde os funcionários são treinados periodicamente. Assim, podemos discutir e trocar ideias adquiridas", e, completando, argumentou que "[...] é a estrutura organizacional da empresa, onde prevalecem os valores empresariais. [...] sua direção contém formação e capacitação para a atividade exercida. A empresa possui uma gestão profissionalizada, seus proprietários são qualificados e os colaboradores são treinados periodicamente". Conforme Padula (1998, p. 55), "[...] a necessidade permanente de profissionalização, assim como a competitividade crescente do mercado exige que a empresa passe por constantes transformações".

Nessa empresa, constatou-se, ainda, que os processos decisórios são centralizados nos gestores, porém um dos entrevistados ressaltou que "[...] decisões de pequenos problemas de rotina, com os quais os funcionários já têm experiência e capacidade de resolver, são por eles tomadas. Estes casos de descentralização do poder, na tomada de decisão, esta medida faz com que os problemas sejam resolvidos com maior rapidez". Segundo Padula (1998, p. 9), "[...] o processo de descentralização é estabelecido com o objetivo de delegar as atividades de gestão operacional e quotidiana da empresa a um grupo de pessoas contratadas [...]".

Os entrevistados das Farmácias CB e Rede também comentaram que "[...] a empresa possui uma rede de interconexões muito característica. Essa rede liga pontos físicos de sua estrutura, como sua localização e a tecnologia com que vende seus produtos e serviços, até pontos intangíveis como a missão a que a empresa se propõe, a imagem que seus funcionários fazem dela, suas relações com seus fornecedores e clientes etc". Ainda, ressaltaram que "[...] a cultura organizacional é a interação entre os diversos elementos constituintes da empresa. A relação e os vínculos entre administradores, trabalhadores e a parte física da empresa". Bornholdt (2005) assevera que, de modo específico, a cultura organizacional envolve, então, experiências, significados, valores e compreensões associados ao meio ambiente, que são aprendidos e compartilhados, e que se expressam, se reproduzem e são comunicados, pelo menos parcialmente, de forma simbólica.

Ao tratar sobre a gestão na empresa Beta Beneficiamento de Couros Ltda, abordou-se sobre a presença de familiares ocupando cargos nesta organização. Ao falar sobre o assunto, os entrevistados ressaltaram que a empresa possui poucos cargos ocupados por familiares. Além disto, um dos entrevistados afirmou que nunca priorizou a contratação de familiares a não-familiares, por acreditar que familiares podem trazer problemas não apenas à empresa, como também à família. Este é um aspecto a ser ressaltado na gestão da empresa, pois, conforme Mincer (2009), a presença de familiares não capacitados na empresa pode resultar na falta de entusiasmo, no abandono da empresa ou na recusa dos que nela estão. Essa capacitação pode estar vinculada à questão treinamento, quer de gestores, de familiares ou de não-familiares, por isso entendemos que o processo de profissionalização está intrinsecamente relacionado à gestão, quanto a distinguir competências e habilidades para o exercício de cargos e responsabilidades na empresa familiar. Mais uma vez detectamos situações que se ligam diretamente a valores da cultura organizacional: tradição, hábitos e costumes arraigados/cristalizados. 
No que diz respeito aos treinamentos realizados na empresa pesquisada, a Beta Ltda, os entrevistados afirmaram que estes são realizados, porém sem a presença dos gestores, uma vez que são voltados para os funcionários dos setores produtivos, sendo treinamentos práticos, como de primeiros-socorros, prevenção de acidentes, entre outros. Ao conceituar treinamento, Oliveira (1999, p. 210) afirma que este é um "[...] processo educacional aplicado de maneira sistemática e organizada sobre a qualificação dos funcionários e executivos da empresa familiar, proporcionando aprendizado de conhecimentos, atitudes e habilidades [...]". Desta forma, evidencia-se a importância da realização de treinamentos, o que Freitas (2009) avalia ser necessário, visando habilitar, tanto a empresa quanto os funcionários, ao nível de competências para fazer, entender e diagnosticar.

Na empresa Beta Beneficiamento de Couros Ltda, questionou-se sobre quais características culturais são percebidas pelos entrevistados na empresa. Sobre isso, um dos entrevistados respondeu: "[...] a cultura organizacional da empresa é forte, possuindo muitos aspectos positivos, sendo um deles a forma como os colaboradores se orientam na organização, sabendo de suas responsabilidades e empenhando-se na realização destas, sem a necessidade de serem constantemente cobrados ou de necessitar de normas escritas [...]". Esse entrevistado também ressalvou que os colaboradores gostam de trabalhar na organização. Sobre isto, Robbins (2005, p. 377) destaca: "[...] em uma cultura forte, os valores essenciais são intensamente acatados e amplamente compartilhados". Evidencia-se com isso, que o comportamento dos funcionários da organização é influenciado pelo clima interno, devido ao alto grau de compartilhamento e intensidade dos valores da cultura presente.

Quanto à gestão da U\&N Transporte, um dos entrevistados ressaltou que "primeiro devemos profissionalizar a empresa e criar a cultura do planejamento. Mas claro que todos os anos o conselho em conjunto define-se certos objetivos, o que hoje seria nosso planejamento". Outro entrevistado seguiu a mesma linha de resposta dizendo que os sócios da U\&N são complacentes a esta estrutura, e citou que a empresa é paternalista, "não possui um planejamento estratégico devido a empresa ser extremamente paternalista. Cabe ressaltar aqui que os sócios que não atuam na empresa são complacentes a esta estrutura". Segundo Casillas, Vásquez e Díaz (2007, p. 102), "dirigir a empresa significa determinar a orientação estratégica para o longo prazo e participar das decisões relacionadas com a atribuição de recursos essenciais de longo alcance". Com isso, pode-se notar que a empresa U\&N não está sendo dirigida da forma que deveria ser, faltando aspectos importantes que poderiam contribuir com o crescimento da empresa ou que pudessem evitar uma possível entropia da organização. Nesse sentido, destaca-se o que relata Bornholdt (2005, p. 117): "cuidar do futuro significa contribuir (pensar, avaliar, sugerir e aprovar) para o posicionamento estratégico, o planejamento estratégico e a implementação das opções estratégicas".

Para os entrevistados da empresa U\&N Transporte, ficou claro que esta empresa não possui uma gestão profissionalizada, pois, segundo um dos comentários: “[...] profissionalização é quando a família, apesar da sociedade e da união, não interfere na gestão do negócio, o que não ocorre na empresa. As pessoas que trabalham na empresa possuem competência para estar nos cargos, ganham conforme prática de mercado e há hierarquia. Não há garantia de emprego, as pessoas possuem metas e estas devem ser garantidas". Nesse sentido, outro entrevistado deu resposta semelhante, relatando que a U\&N não possui uma gestão $100 \%$ profissionalizada, e que profissionalização é quando a empresa consegue planejar e executar suas funções de forma clara e objetiva, ou seja, quando possui pessoas capazes de desenvolver as atividades propostas por determinado cargo. De acordo com Morais (2009), a profissionalização de uma empresa depende da atuação dos profissionais em seus cargos. Esses entrevistados deveriam ser capacitados com 
a finalidade de desenvolver aptidões e atitudes exigidas pela função a ser realizada, ou seja essas pessoas teriam de ser as melhores para cada cargo proposto.

Em relação à cultura organizacional, na empresa U\&N Transporte foram evidenciados nas respostas obtidas diversos aspectos que os entrevistados manifestaram como positivos, tratando-se da cultura da organização. Entre o que foi citado, destacaram-se a história da empresa, o perfil do fundador, a união da família, o clima organizacional, a estabilidade da empresa/credibilidade, a ética e o compromisso com o cliente, a sinceridade, a honestidade em todo o negócio, a solidariedade com a comunidade e a preocupação com os funcionários. Levando em conta o espírito do fundador, como uma pessoa visionária, batalhadora, apaixonada pela família, entre outras, Casillas, Vásquez e Díaz (2007, p. 35), ressaltam que “[...] a cultura é formada pelo compartilhamento de experiências e pela realização de um aprendizado comum, principalmente por parte de quem lidera a organização e dos seus colaboradores mais importantes". É possível notar, então, que o fundador ainda possui grande influência quando se refere à cultura organizacional da empresa U\&N, tendo em vista que todos os entrevistados destacaram a presença marcante desse fundador na gestão das empresas.

O processo decisório é um aspecto importante no sistema de gestão da empresa familiar. Os entrevistados da empresa Estofados Estilo, quando questionados sobre a maneira como as decisões são tomadas na organização, posicionaram-se que este processo é descentralizado. As decisões que dizem respeito a toda empresa são tomadas pelos sócios através de reuniões com a gerência, porém, quando ocorrem problemas rotineiros, cada setor é responsável por este processo. Conforme essas respostas, pode-se concluir que, quando torna-se necessário tomar uma decisão, é importante que se leve em consideração a linha de pensamento dos gestores.

A empresa Estofados Estilo, segundo os seus entrevistados, possui um plano de promoção e ascensão profissional definido, porém este não é formalizado. Conforme Padula (1998, p. 82), "[...] deve-se entender administração profissional como um sistema de gestão em que se utilizam sistemas formais para o planejamento, a organização e o controle da ação empresarial". Sendo assim, para a empresa em estudo tornar-se profissionalizada, é necessário que formalize seus processos de gestão. A empresa, segundo os entrevistados, apresenta uma política de progressão de faixa salarial que é de conhecimento de todos os funcionários; sendo assim, "todos sabem até onde podem chegar". Conforme os depoimentos obtidos, os principais critérios observados para promover os colaboradores são a disciplina, a dedicação pela empresa, a experiência e a capacidade de produção.

Um dos aspectos positivos percebidos pelos entrevistados com relação à cultura da empresa Estofados Estilo é a boa relação entre os diretores e subordinados, que interagem diretamente, o que deve proporcionar maior motivação aos colaboradores da empresa. De acordo com Oliveira (1999, p. 193), “[...] conhecer os níveis hierárquicos mais baixos é também uma forma de o líder identificar-se com seus liderados. Ao atuar nesse sentido, o líder reforça seu relacionamento com os liderados, pois há, de sua parte, uma dose de interação que lhe confere autenticidade". Esta interação se dá por meio de eventos, esportivos ou não, promovidos pela associação de funcionários, e na preocupação dos sócios com o bem-estar dos colaboradores. Acredita-se que estes valores cultivados pelos sócios da empresa vêm "de casa" e que, segundo os entrevistados, isto aconteça devido a empresa ser familiar. Outro hábito que estreita as relações entre funcionários e chefia, citado pelos entrevistados, é o hábito de tomar chimarrão todos os dias. Além deste ritual diário, os entrevistados destacam que na data de aniversário é dado presente aos funcionários. Segundo Freitas (2009), os ritos "[...] são os eventos, em geral, que ocorrem dentro da organização e fazem com que a cultura se torne mais visível". 


\subsection{Discussão da análise}

Neste tópico, apresentamos de maneira sucinta um apanhado geral do que resultou a a análise realizada no estudo de casos múltiplos em cinco (5) empresas de pequeno e médio porte, do segmento serviços, na região do vale do Sinos/RS.

A partir do que se apresenta no Quadro 1, pode-se afirmar que os processos de gestão e governança nas empresas foco deste estudo ainda são pouco qualificados e sistematizados. Isso implicaria em problemas administrativos de gestão que, por sua vez, redundariam em certos "atropelos" organizacionais e gerenciais. Com lacunas na ordem da gestão e da governança nessas empresas familiares, prevê-se existir dificuldades na condução de processos ligados à profissionalização.

Por fim, pode-se dizer que a gestão e a governança nas empresas familiares são de extrema importância para a obtenção de resultados eficazes, pois o não controle ou a equivocada tomada de decisão podem ocasionar dificuldades e complicações na administração da empresa.

\begin{tabular}{|l|l|}
\hline \multicolumn{2}{|c|}{ Síntese da Gestão e Governança } \\
\hline - Empreendedorismo & $\begin{array}{l}\text { Constatou-se que as organizações estudadas, assim como a grande maioria das } \\
\text { empresas familiares, surgiu devido ao empreendedorismo de seu fundador, que } \\
\text { abriu o negócio na busca de novas oportunidades, assumindo risco para isto. }\end{array}$ \\
\hline 3- Planejamento estratégico & $\begin{array}{l}\text { Nas empresas analisadas, não há um planejamento estratégico formal e orga- } \\
\text { nizado, porém estas instituições possuem sua missão, seus valores e princípios } \\
\text { definidos. }\end{array}$ \\
\hline V-Processo decisório & $\begin{array}{l}\text { Na empresa Estofados Estilo, o processo decisório é descentralizado. Nas demaingin- } \\
\text { do-se ao seu fundador e alguns familiares mais próximos desse instituidor. } \\
\text { organizações estudadas, este processo ocorre de forma centralizada, não exis- } \\
\text { tindo um conselho administrativo responsável pela tomada de decisões. Estas } \\
\text { são tomadas, em grande maioria, unicamente pelo diretor da empresa, sendo os } \\
\text { assuntos discutidos anteriormente com os envolvidos, em reuniões periódicas. }\end{array}$ \\
\hline
\end{tabular}

Quadro 1 - Quadro-síntese dos principais aspectos da gestão e da governança nas empresas estudadas

Fonte: Elaborado pelos autores com base nas entrevistas realizadas

Na sequência, com base no que consta no Quadro 2, percebe-se a nítida diferenciação entre as empresas objeto deste estudo. A profissionalização da gestão ainda é incipiente na maioria delas, o que, de alguma maneira, repercute lacunarmente na governança dessas organizações familiares. Ou seja, a administração empresarial familiar ainda persiste com maior ênfase na "tradição" e na "cultura" do que na eficácia da governança para a profissionalização da gestão.

\section{Síntese da Profissionalização}

\begin{tabular}{|l|l|}
\hline \multicolumn{2}{|c|}{ Síntese da Profissionalização } \\
\hline 1 - Qualificação & $\begin{array}{l}\text { Na opinião dos entrevistados, as empresas IB Ltda e U\&N Transporte não possuem uma } \\
\text { gestão profissionalizada. Nas demais organizações pesquisadas, a gestão encontra-se } \\
\text { satisfatoriamente qualificada, havendo interação entre funcionários e familiares, na } \\
\text { busca do sucesso da organização - destacam-se as empresas Farmácias CB e Redes. }\end{array}$ \\
\hline 2-Treinamentos & $\begin{array}{l}\text { Ocorrem treinamentos nas empresas, porém, a maioria voltada para cunho prático, } \\
\text { para os setores produtivos da organização. }\end{array}$ \\
\hline 3- Plano de promoção & $\begin{array}{l}\text { Na empresa Estofados Estilo, há um plano de promoção e ascensão profissional defini- } \\
\text { do, porém, este não é formalizado. Nas demais empresas analisadas não existem planos } \\
\text { de promoção. Essa inexistência foi justificada pelo porte das organizações, sendo os } \\
\text { funcionários promovidos, ocasionalmente, pelas competências demonstradas. }\end{array}$ \\
\hline
\end{tabular}

Quadro 2-Quadro-síntese dos principais aspectos da profissionalização nas empresas estudadas

Fonte: Elaborado pelos autores com base nas entrevistas realizadas 
Entende-se, então, que a profissionalização da gestão nas empresas familiares é de expressiva importância, pois, só assim, o futuro da organização será encaminhado de forma segura e com resultados eficientes e eficazes.

Em relação à síntese demonstrada no Quadro 3, tem-se que a cultura molda fortemente as relações intraorganizacionais, de maneira que, às vezes, facilita processos e a própria gestão e, em outras, dificulta o avanço no sentido de profissionalizar as empresas, no que diz respeito à gestão e à governança. Dessa maneira, entende-se que as referidas empresas familiares poderiam atentar mais para os aspectos culturais de cada uma delas, no sentido de trabalhar e inserir novos conceitos administrativos quanto às suas práticas.

\begin{tabular}{|l|l|}
\hline \multicolumn{2}{|c|}{ Síntese da Cultura Organizacional } \\
\hline 1 - Estruturas de poder & $\begin{array}{l}\text { Nas empresas estudadas, a cultura organizacional presente caracteriza-se pela } \\
\text { boa relação entre os funcionários, devido à identificação e relação entre estes e } \\
\text { os valores da organização. }\end{array}$ \\
\hline 2- Normas informais & $\begin{array}{l}\text { Nas organizações pesquisadas, mesmo não havendo algumas normas escritas, os } \\
\text { funcionários se orientam e realizam suas tarefas sem estas regras formais, devido } \\
\text { à cultura presente e já solidificada. }\end{array}$ \\
\hline 3-Resistência a mudanças & $\begin{array}{l}\text { Caracterizada como forte pelos entrevistados das empresas estudadas, um as- } \\
\text { pecto negativo abordado deu-se pela resistência à mudanças, característica de } \\
\text { culturas como esta onde ocorrem dificuldades em modificações de certos hábitos } \\
\text { já arraigados. }\end{array}$ \\
\hline
\end{tabular}

Quadro 3-Quadro-síntese dos principais aspectos da cultura organizacional nas empresas estudadas

Fonte: Elaborado pelos autores com base nas entrevistas realizadas

Para finalizar, observa-se que a cultura organizacional das empresas, além de formar valores e crenças, interfere ativamente nas negociações de administração que essas empresas possuem, tanto com clientes quanto com fornecedores, e ainda interfere positiva ou negativamente na continuidade do empreendimento, ou seja, na própria sucessão da gestão na empresa familiar.

\section{CONSIDERAÇÕES FINAIS}

O estudo desenvolvido sobre gestão de empresas familiares foi realizado em empresas familiares de pequeno e médio porte da região do Vale do Sinos/RS, a fim de compreender a forma de gestão e governança, a profissionalização e a cultura organizacional identificadas nessas empresas. Esse estudo foi importante para que os pesquisadores analisassem sobre a importância da sua contribuição, em termos de subsídios, que poderá oferecer às empresas familiares de pequeno e médio porte, do segmento serviços, no que diz respeito às boas práticas de gestão, de governança, de profissionalização, todas essas variáveis organizacionais que impactam sobremaneira os rumos e a perpetuidade dessas organizações.

Em relação às questões norteadores do problema de pesquisa, verificou-se que os entrevistados nas empresas estudadas, em síntese, possuem o entendimento de profissionalização, mas, na prática, a gestão mantém-se centralizada entre os familiares. Dessa forma, apresentamse alguns aspectos relacionados a uma empresa familiar profissionalizada, porém em nível pouco representativo para tornar, de fato, essa gestão assim caracterizada. Destaca-se a cultura organizacional nas empresas como fator impactante no processo de profissionalização e de gestão, sendo a cultura organizacional forte influenciadora para a situação de "zona de conforto", que faz com que os gestores não iniciem, ou posterguem, mudanças organizacionais mais efetivas, mais condizentes com o cenário mercadológico em sua competitividade. 
Sobre o objetivo geral, que consistia em investigar e analisar os processos de gestão e de governança, de profissionalização e de cultura organizacional das empresas familiares de pequeno e médio porte, segmento comércio, na região do Vale do Sinos/RS, pode-se concluir que este foi atingido, de forma que o pesquisador utilizou-se da fundamentação teórica e da análise entre a prática e a teoria para aprofundar o conhecimento e confirmar os resultados da análise.

Nesse sentido, tornou-se possível concluir que todos os objetivos específicos foram alcançados. Quanto ao objetivo especifico "a", o pesquisador compreendeu a forma de gestão e de governança, através das entrevistas, e assim foi possível verificar sua adequabilidade em relação à teoria que fundamentou este estudo. Em relação ao objetivo especifico "b", a análise das entrevistas e da teoria foi importante para o entendimento da profissionalização. Por fim, o objetivo específico "c" identificou e analisou a cultura organizacional, por meio das respostas das entrevistas e também dos entendimentos inscritos nas respostas.

Este trabalho possibilitou ampliar conhecimentos para o aprimoramento científico dos pesquisadores, em relação ao conhecimento teórico adquirido e ao aprimoramento da análise e da interpretação das teorias relacionadas à prática. Também ressalta-se a importância desta pesquisa para a vida profissional dos autores, pois oportunizou uma análise mais apurada da gestão realizada em empresas familiares do Vale do Sinos/RS.

Destaca-se, ainda, que este estudo poderá contribuir para a imensa rede de empresas familiares brasileiras, pois apresenta em seu corpo abordagens de casos múltiplos que tematizam as empresas familiares - o tipo mais frequente de organização no Brasil -, apresentando as formas e processos da gestão e da governança, da profissionalização e da cultura organizacional. Além disso, ainda é contributivo para as empresas no sentido de fundamentar conhecimentos que subsidiem futuros processos e aperfeiçoamentos na gestão e na governança, o que repercutiria favoravelmente na profissionalização e, por consequência, na própria sucessão administrativa.

No que diz respeito a futuros estudos, sugere-se um maior aprofundamento quanto aos aspectos culturais das empresas familiares, pois se observou o grande impacto desses nos processos da organização. Desta forma, acredita-se que há muito a se explorar nesse sentido.

Ainda, como sugestão para futuros estudos, recomenda-se a ampliação do número de empresas a serem estudadas, o que aumentaria a possibilidade de outras análises significativas e, consequentemente, resultados mais expressivos. Também, sugerem-se estudos em empresas de grande porte, para que, desta forma, estabeleça-se um comparativo entre os resultados deste e de outros estudos similares.

Por fim, encerra-se esta pesquisa salientando a importância da permanente atenção no que se refere aos processos de gestão e de governança, de profissionalização e de cultura organizacional das empresas familiares, sempre se atendo à profissionalização, visando a melhores práticas de administração. Dessa maneira, busca-se maior competitividade, rentabilidade e participação de mercado e, por consequência, a própria perpetuidade das empresas familiares. 


\section{REFERÊNCIAS}

ADAMS, Jennifer. Growing a family business step by step. Stone World, Troy, EUA, v. 26, nov. 2009.

BERNHOEFT, Renato; GALLO, Miguel. Governança na Empresa Familiar: gestão, poder, sucessão. 4 ed. Rio de Janeiro: Elsevier, 2003.

BORNHOLDT, Werner. Governança na Empresa Familiar: implementação e prática. Porto Alegre: Bookman, 2005.

CASILLAS, José Carlos; VÁZQUEZ, Adolfo; DÍAZ, Carmen. Gestão da Empresa Familiar: conceitos, casos e soluções. São Paulo: Thomson, 2007.

CAVE, Damien. Family Businesses Are Reeling In Recession. New York Times, New York, EUA, jul. 14, 2009.

COKER, Craig. Composting integrated into family business. BioCycle, Emmaus, EUA, v. 50, n. 10, p. 11, 2009.

DAVEL, E.; COLBARI, A. Organizações Familiares: Por uma Introdução a sua Tradição, Contemporaneidade e Multidisciplinaridade. Revista Organizações \& Sociedade, v. 7, n. 18, p. 45-64, 2000,

FREITAS, Ernani Cesar de. A Força e o Potencial de Crescimento das Empresas Familiares. Jornal ABC, Novo Hamburgo - RS, p.8, nov. 2009.

FREITAS, Ernani Cesar de; FREZZA, Cleusa Maria Marques. Gestão e Sucessão em Empresa Familiar. Gestão e Desenvolvimento, Novo Hamburgo, RS, v. 2, n. 1, p. 31-43, jan. 2005.

GEHLEN, Mara Vania Dopke. A Profissionalização da Gestão em Empresas Familiares: um estudo de caso da Artecola S/A. 2006. 112 f. Monografia (Conclusão do Curso de Administração - Habilitação em Administração de Empresas), Feevale, Novo Hamburgo, 2006.

GIL, Carlos Antonio. Métodos e Técnicas da Pesquisa Social. 5 ed. São Paulo: Editora Atlas, 2006.

GRZYBOVSKI, Denize; TEDESCO, João Carlos (Orgs). Empresa familiar: tendências e racionalidades em conflito. Passo Fundo - RS: UPF, 2000.

MARCONI, Marina de Andrade; LAKATOS, Eva Maria. Técnicas de pesquisa: planejamento e execução de pesquisas, amostragens e técnicas de pesquisa, elaboração, análise e interpretação de dados. 4 ed. São Paulo - SP: Atlas, 1999.

MINCER, Jilian. Family Business - The Family That Works Together Should Pay Together. Wall Street Journal, New York, EUA, jul. 13, v. 10, n. 3, p. 6, 2009.

MORAIS, Richard C. Save the Family Business. Forbes, New York, EUA, v. 183, n. 10, 2009.

OLIVEIRA, Djalma de Pinho Rebouças de. Empresa Familiar: como fortalecer o empreendimento e otimizar o processo sucessório. São Paulo: Atlas, 1999.

PADULA, Antônio Domingos. Empresa familiar: profissionalização, desenvolvimento e sucessão. Porto Alegre, RS: SEBRAE/RS, 1998.

PRODANOV, Cleber Cristiano; FREITAS, Ernani Cesar de. Metodologia do Trabalho Científico: métodos e técnicas da pesquisa e do trabalho acadêmico. Novo Hamburgo: Feevale, 2009.

ROBBINS, Stephen P. Comportamento Organizacional. 11 ed. São Paulo: Pearson Prentice Hall, 2005.

SEGRÈ, Gino. The Family Business. Technology Review, Cambridge, v. 112, n. 2, p. 5, 2009.

YIN, Robert K. Estudo de caso: planejamento e métodos. 3. ed. Porto Alegre, RS: Bookman, 2005. 


\title{
APÊNDICE A - ENTREVISTA NÃO-ESTRUTURADA
}

\author{
Prezado(a) senhor,
}

Com o objetivo de investigar e analisar os processos de gestão e profissionalização das empresas familiares de pequeno e médio porte, segmento comércio, na região do Vale do Sinos/ RS, solicitamos-lhe a gentileza de responder a entrevista a seguir. Este instrumento tem a finalidade de entender e relacionar a repercussão desses processos na realidade organizacional das empresas familiares pesquisadas.

1. Como a empresa foi fundada? Como você define o perfil do fundador ou principal gestor da sua empresa? Há quanto tempo você atua como diretor da empresa?

2. Quantas pessoas são proprietárias da organização? Destas pessoas proprietárias, quantas trabalham efetivamente na empresa e que cargos ocupam?

3. Existe um planejamento estratégico formal e organizado na empresa? Explique como ele é. Se não, por que a empresa não possui.

4. De que maneira ocorrem os processos decisórios na empresa? Existe um conselho administrativo ou as decisões são tomadas pontualmente?

5. Considerando o aspecto desenvolvimento da família empresária, em qual estágio a empresa se encontra?

6. Os familiares que desempenham cargos de administração participam de treinamentos internos? Quais? Participam de treinamentos externos? Quais?

7. Quais habilidades e competências são necessárias para administrar e prosperar a empresa?

8. O que você entende por profissionalização na empresa familiar? Você acredita que sua empresa possui uma gestão profissionalizada? Em caso positivo, explique como foi o processo e de que forma a empresa profissionalizou a gestão? Em caso negativo, explique porque ainda não profissionalizou sua gestão.

9. A empresa tem um plano de promoção e ascensão profissional definido e organizado? A partir de quais critérios os colaboradores são promovidos?

10. Quais são as principais qualidades que os lideres levam em consideração para a contratação de um funcionário? Sendo familiar ou não, isso faz diferença?

11. Considerando a Cultura Organizacional como o conjunto de normais informais que orientam o comportamento dos membros de uma organização e que direcionam suas ações para o alcance dos objetivos: Quais características você evidencia na cultura da empresa? Quais aspectos positivos e negativos podem ser percebidos com relação a esta?

12. O que você espera ou como gostaria de ver a sua empresa no futuro? Qual o seu objetivo empresarial? 
DE PAI PARA FILHO: A COMPLEXIDADE E OS DESAFIOS DA

GESTÃO DAS EMPRESAS FAMILIARES

Rev. AdM. UfSM, SANTA MARIA, v. 5, N. 3, P. 549-568, SET./DEZ. 2012

-568 - 